produces materials with high specific surface area, which must be accounted for when comparing reactivities of materials prepared by different routes. Overall, compositions such as $\mathrm{BaCe}_{0.7} \mathrm{Zr}_{0.2} \mathrm{Nd}_{0.1} \mathrm{O}_{3}$ provided a good compromise between high stability and high conductivity.

These combinations also show a potential improvement in fuel cell performance, since they allow lower operation temperatures than $\mathrm{ZrO}_{2}$ electrolytes. Doped perovskites oxides obtained with different chemical characteristics will make it possible to obtain a range of materials with competitive conditions to be used in fuel cell applications.

SIARI S. SOSA

\section{Infrared Absorption Measurements Confirm the Existence of an Isolated Hydrogen Defect in Proton-Implanted Germanium}

An international research team from the Institute of Physics and Astronomy of Aarhus University in Denmark and the Department of Physics and Astronomy of Vanderbilt University in Nashville, Tennessee has identified the origin of two isolated hydrogen defects in high-resistivity, ultrapure Ge single crystals implanted with protons at cryogenic temperatures. As reported in the October 2 issue of Physical Review Letters, the samples were implanted with protons and/or deuterons at multiple energies, yielding uniform concentration profiles, with widths between 20 and $200 \mu \mathrm{m}$. The samples were cooled to either 20 or $80 \mathrm{~K}$ during implantation. During the transportation from the implantation site to the infrared spectrometer, the samples were kept continuously cooled to within $10 \mathrm{~K}$ ofthe implantation temperatures, and the in situ infrared absorption (IRAS) measurements were performed at $\sim 10 \mathrm{~K}$ with a spectral resolution better than $0.8 \mathrm{~cm}^{-1}$.

From the IRAS measurements, two distinctive lines were obtained: $745 \mathrm{~cm}^{-1}$ and $1794 \mathrm{~cm}^{-1}$. While the properties of the 1794 $\mathrm{cm}^{-1}$ mode are similar to the stretch mode of bond center $\mathrm{H}$ in $\mathrm{Si}$, the $745 \mathrm{~cm}^{-1}$ has no Si analogue. Two different approaches have shown that the two lines originate from different defects. From isochronal annealing, the line at $745 \mathrm{~cm}^{-1}$ starts to decrease at $100 \mathrm{~K}$ while the $1794 \mathrm{~cm}^{-1}$ line anneals at $210 \mathrm{~K}$. Varying the H concentration has shown that the intensity of the $1794 \mathrm{~cm}^{-1}$ line is proportional with the concentration of hydrogen over the whole range covered, while the intensity of the $745 \mathrm{~cm}^{-1}$ line maintains the proportionality just below $2 \times 10^{18} \mathrm{~cm}^{-3}$, at which it saturates.

From stress measurements and symmetry considerations, the line at $1794 \mathrm{~cm}^{-1}$ is attributed to $\mathrm{H}_{B C}^{(+)}$in $\mathrm{Ge}$. For the line observed at $745 \mathrm{~cm}^{-1}$, the measurement seems to support the idea of an isolated $\mathrm{H}$ located on a $<111>$ axis of the Ge lattice, and vibrating perpendicular on this axis, corresponding to an isolated $\mathrm{H}^{(-)}$near the tetrahedral site. Although predicted by theory more than a decade ago, this work provides direct observation of this isolated hydrogen species in a semiconductor.

Claudiu Muntele

\section{Hänsch Receives ICALEO ${ }^{\circledR} 2000$ Schawlow Award}

Theodor W. Hänsch, director of MaxPlanck-Institute for Quantum Optics and professor of physics at the University of Munich, Germany, has been named the Arthur L. Schawlow Award recipient by the Laser Institute of America in recognition of his pioneering research in high resolution laser spectroscopy. He is recognized worldwide as the initiator of research testing basic physics laws with techniques of precise laser spectroscopy and the cooling and manipulation of atomic matter with laser light. Hänsch was the Honored Speaker at the Awards luncheon of the 19th International Congress on Applications of Lasers \& Electro-Optics (ICALEO ${ }^{\circledR}$ ) held October 2-5 in Dearborn, Michigan.

\section{Chain T. Liu Receives 2001 Acta Metallurgica Gold Medal}

The 2001 Acta Metallurgica Gold Medal has been awarded to Chain T. Liu, Senior Corporate Fellow at Oak Ridge National Laboratory. Liu is world renowned for his leadership and outstanding achievements in research on ordered intermetallics based on aluminides and silicides. He has played a key role in advancing the science and developing the technology of intermetallic alloys for use as new structural materials. Liu will be presented with the medal on February 13, 2001 in New Orleans during the 130th TMS Annual Meeting. $\square$

MRS Futule Meetings

\section{Fall Meeting}

November 26-30

Exhibit: November 27-29

Boston, Massachusetts

\section{Meeting Chairs:}

Bruce M. Clemens

Stanford University

Tel $650-725-7455$

Fax 650-725-4034

clemens@soe.

stanford.edu

Jerrold A. Floro

Sandia National

Laboratories

Tel $505-844-4708$

Fax 505-844-1197

jafloro@sandia.gov
Julia A. Kornfield

California Institute of

Technology

Tel 626-395-4138

Fax 626-568-8743

jak@cheme.caltech.edu

\section{Yuri Suzuki}

Cornell University

Tel 607-255-6429

Fax 607-255-2365

suzuki@ccmr.cornell.edu

2002 Spring Meeting

April 1-5

Exhibit: April 2-4

San Francisco, California

Meeting Chairs:

Zhenan Bao

Bell Labs

Lucent Technologies

Tel 908-582-4716

Fax 908-582-4868

zbao@lucent.com

Eugene A. Fitzgerald

Massachusetts Institute

of Technology

Tel 617-258-7461

Fax 617-253-3046

eafitz@mit.edu

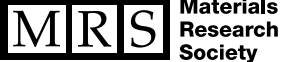

506 Keystone Drive, Warrendale PA 15086-7573 USA Tel: 724-779-3003 • Fax: 724-779-8313 • info@mrs.org
2002 Fall Meeting

December 2-6

Exhibit: December 3-5

Boston, Massachusetts

Meeting Chairs:

Marie-Isabelle Baraton

University of Limoges

Tel $\quad 33-555-457348$

Fax 33-555-778100

baraton@unilim.f

Eric L. Garfunkel

Rutgers University

Tel 732-445-2747

Fax 732-445-5312

garf@rutchem.

rutgers.edu
David C. Martin

University of Michigan

Tel 734-936-3161

Fax 734-763-4788

milty@umich.edu

Stuart S. P. Parkin

IBM Almaden

Research Center

Tel $\quad 408-927-2390$

Fax 408-927-2395

parkin@almaden.

ibm.com 